Electrical properties of high-pressure reactive sputtered thin hafnium oxide high- $k$ gate dielectrics

This content has been downloaded from IOPscience. Please scroll down to see the full text. 2007 Semicond. Sci. Technol. 221344

(http://iopscience.iop.org/0268-1242/22/12/019)

View the table of contents for this issue, or go to the journal homepage for more

Download details:

IP Address: 147.96.14.15

This content was downloaded on 12/02/2014 at 17:41

Please note that terms and conditions apply. 


\title{
Electrical properties of high-pressure reactive sputtered thin hafnium oxide high- $k$ gate dielectrics
}

\author{
S Dueñas ${ }^{1}$, H Castán ${ }^{1}$, H García ${ }^{1}$, A Gómez ${ }^{1}$, L Bailón ${ }^{1}$, \\ M Toledano-Luque ${ }^{2}$, I Mártil ${ }^{2}$ and G González-Díaz ${ }^{2}$ \\ ${ }^{1}$ Departamento de Electricidad y Electrónica, ETSI Telecomunicación, Universidad de \\ Valladolid, Campus 'Miguel Delibes', 47011 Valladolid, Spain \\ ${ }^{2}$ Departamento de Física Aplicada III (Electricidad y Electrónica), Facultad de Ciencias \\ Físicas, Universidad Complutense, 28040 Madrid, Spain \\ E-mail: sduenas@ele.uva.es
}

Received 9 July 2007, in final form 20 September 2007

Published 15 November 2007

Online at stacks.iop.org/SST/22/1344

\begin{abstract}
Thin films of hafnium oxide have been deposited by the high-pressure reactive sputtering (HPRS) system. In this growth system the deposition pressure is around $1 \mathrm{mbar}$, three orders of magnitude higher than in the conventional ones, assuring that both reflected and sputtered particles reach the substrate with a low energy. The amorphous or polycrystalline structure is modified by adjusting the ratio of oxygen to argon of the sputtering gas. The electrical characteristics of both polycrystalline and amorphous films are compared. In all cases, the leakage current can be fitted to Poole-Frenkel emission. Amorphous films show the best characteristics in terms of capacitance-voltage behaviour, leakage current and interfacial state density, with conductance and flat-band voltage transients almost negligible.
\end{abstract}

\section{Introduction}

The scaling down of the metal-oxide-semiconductor field effect transistor (MOSFET) allows the integration of a larger number of devices on chip with higher speed. At the future scales of integration, the leakage currents through the $\mathrm{SiO}_{2}$ gate are intolerable due to the high power consumption [1]. A physically thicker layer with higher dielectric constant is necessary to replace the $\mathrm{SiO}_{2}$. As a temporary solution, the industry has incorporated the nitridation of the oxide layer [2-4], increasing the dielectric constant to 7. However, a more aggressive downscaling of the transistor dimension pushes the use of materials with higher dielectric constant $[5,6]$. Hafnium oxide and $\mathrm{Hf}$ silicate dielectrics are among the most promising of such materials [7-10]. The use of these dielectrics reduces the leakage currents to the values required by the International Technology Roadmap for Semiconductors (ITRS) [11]. However, important issues such as threshold and flat-band shift [12], charge trapping [13, 14], bulk traps $[15]$ and bias temperature instability $[16,17]$ still have to be thoroughly studied.
In this work, the electrical properties of hafnium oxide grown by high-pressure reactive sputtering (HPRS) [18] are studied. It is well known that the structure and physical properties of the films grown by sputtering strongly depend on the energy deposited by the particles that reach the substrate [19]. In the HPRS system, the working pressure is around 1 mbar, three orders of magnitude higher than the conventional sputtering system. Due to the high pressure, the mean free path of the processing gas, either $\mathrm{O}_{2}$ or Ar, is significantly short (around $0.05 \mathrm{~mm}$ ) [20]. Therefore, the sputtered and reflected particles emitted from the target collide with the gas medium, losing energy, and thermalize within a short distance, around $0.16 \mathrm{~cm}$ for sputtered atoms and $0.27 \mathrm{~cm}$ for reflected atoms [20]. The thermalization length is much shorter than the target-substrate distance $(2.5 \mathrm{~cm})$, and the transport of sputtered particles to the substrate is due to a purely diffusional process. Consequently, the energy deposited by reflected and sputtered atoms should be low, preventing damage of the substrate and the growing film itself independently of the working gas. In spite of this, we have recently observed in this system that the films deposited with mixed $\mathrm{O}_{2} /$ Ar plasmas present significant differences. Indeed, the samples deposited 
in atmospheres containing oxygen became polycrystalline, conversely to the films deposited with pure Ar that were amorphous [21]. All these outcomes led us to perform a deeper analysis of the physical properties and growth kinetics of the high-pressure sputtered $\mathrm{HfO}_{2}$ as a function of the argon to argon plus oxygen ratio. Moreover, the differences in the electrical properties between amorphous and polycrystalline films are also explored by using the following techniques: current-voltage $(I-V)$, capacitance-voltage $(C-V)$, deep level transient spectroscopy (DLTS), conductance transients $(G-\mathrm{t})$ and constant-capacitance flat-band voltage transients $\left(V_{\mathrm{FB}}-\mathrm{t}\right)$.

\section{Experimental details}

A preliminary study of the $\mathrm{HfO}_{2}$ properties of the films deposited in an argon/oxygen mixture was presented in a previous work [21]. It was observed that the samples deposited in pure argon present an amorphous structure and their electrical properties (interface trap density and dielectric constant) are improved compared with polycrystalline ones. In this work, the oxygen to argon ratio was varied keeping the pressure constant (1.2 mbar), in order to deepen the influence of the sputtering atmosphere on the physical and electrical characteristics of the samples. Let $R$ be the argon flow to argon plus oxygen flow ratio: $R=\Phi(\mathrm{Ar}) /\left(\Phi(\mathrm{Ar})+\Phi\left(\mathrm{O}_{2}\right)\right)$. This parameter varied between $R=0$ (only oxygen as sputtering gas) and $R=1$ (only argon as sputtering gas).

Hafnium oxide films were grown on $\left(\begin{array}{lll}1 & 0 & 0\end{array}\right)$ n-type low resistivity $(5 \Omega \mathrm{cm})$ silicon substrates except the films for infrared spectroscopy measurements which were grown on (1 111$)$ p-type high resistivity $(200 \Omega \mathrm{cm})$ silicon substrate. Before the film deposition, substrates were submitted to a standard RCA (Radio Corporation of America) cleaning [22]. The growing temperature was kept at $200{ }^{\circ} \mathrm{C}$, the RF power was $60 \mathrm{~W}$ and the deposition time was $30 \mathrm{~min}$. After the film deposition, aluminium dot electrodes $\left(0.102 \mathrm{~mm}^{2}\right)$ were e-beam evaporated through a shadow mask.

The structure and physical properties of the films were investigated by $\mathrm{x}$-ray diffraction, Fourier transform infrared spectroscopy (FTIR) and transmission electron microscopy (TEM). Glancing incidence $\mathrm{x}$-ray diffraction (XRD) was performed to study the crystallinity of the films using a Panalytical X'Pert PRO MRD diffractometer with $\mathrm{Cu} \mathrm{K} \alpha$ radiation at $0.5^{\circ}$ incidence angle. IR spectra were taken with a Nicolet Magna-IR spectrometer in transmission mode and normal incidence. The film and interface morphology and thickness were investigated by transmission electron microscopy (TEM) using a JEOL JEM-2000 FX microscope operated at $200 \mathrm{keV}$. This microscope is equipped with an energy dispersive x-ray (EDX) spectrometer.

In order to record the electrical parameters at several temperatures varying between $77 \mathrm{~K}$ and room temperature, samples were first cooled in darkness from room temperature to $77 \mathrm{~K}$ at zero bias in an Oxford DM1710 cryostat. An Oxford ITC 502 controller was used to monitor the temperature during the measurements. The capacitancevoltage measurements were carried out with the assistance of a Boonton 72B capacitance meter and a Keithley 617 programmable electrometer. The capacimeter makes measurements of shunt capacitance by applying a $1 \mathrm{MHz}$ and
$15 \mathrm{mV}$ level ac signal test. Voltage bias consists of $50 \mathrm{mV}$ steps. The capacitance measurements are made $10 \mathrm{~s}$ after the bias voltage step is applied, in order to prevent transient instabilities in the capacitance values. The current-voltage curves were measured with a Keithley 6517A programmable electrometer in the stair sweep voltage mode while the voltage step used was $5 \mathrm{mV}$. For DLTS measurements we used a $1 \mathrm{MHz}$ Boonton 72B capacitance meter and a HP54501 digital oscilloscope to record the capacitance transients. A Keithley 617 programmable electrometer is used together with a HP214B pulse generator to introduce the quiescent bias and the filling pulse, respectively. The experimental set-up of the conductance transient technique consists of an HP 33120A arbitrary wave form generator to apply the bias pulses, an EG\&G 5206 two-phase lock-in analyser to measure the conductance and a HP 54501A digital oscilloscope to record the complete conductance transient. Finally, a Keithley 6517A working as programmable bias source and a $1 \mathrm{MHz}$ Boonton 72B capacitance meter were used for recording flatband voltage transients at constant capacitance.

\section{Results and discussion}

\subsection{Structure and growth kinetics of the films}

The $\mathrm{x}$-ray diffractograms of figure 1 demonstrate that samples deposited in $\mathrm{O}_{2}$ or $\mathrm{O}_{2} / \mathrm{Ar}$ plasmas are polycrystalline while samples deposited in pure Ar plasma are amorphous. Vertical lines in the figure mark the characteristic peaks of the $\mathrm{HfO}_{2}$ monoclinic phase. Clearly, the diffractograms of the samples deposited with $\mathrm{O}_{2}$ plasma or mixed $\mathrm{O}_{2} / \mathrm{Ar}$ plasmas present the diffraction peaks associated with the monoclinic structure [23]. Therefore, all the samples deposited in an atmosphere containing oxygen grow according to the monoclinic phase. In addition, a decrease in the height of the diffraction peaks is observed with increasing $R$ ratio, which is associated with a decrease of the $\mathrm{HfO}_{2}$ thickness, i.e. deposition rate, as we will see in the section related to TEM measurements. Conversely, the diffractogram of the sample deposited in $\operatorname{Ar}$ plasma $(R=$ 1 ) does not present any diffractogram peak, indicating that it is necessary to completely remove the presence of $\mathrm{O}_{2}$ to obtain amorphous films.

Figure 2 shows the FTIR spectra of several samples deposited in different $\mathrm{O}_{2} / \mathrm{Ar}$ atmospheres. There are peaks situated at 748, 647, 601 and $512 \mathrm{~cm}^{-1}$ for the samples deposited with $R<1$, and a single peak at $601 \mathrm{~cm}^{-1}$ for the sample deposited with $R=1$. This result indicates that the peak situated at $601 \mathrm{~cm}^{-1}$ is related to amorphous and crystalline $\mathrm{HfO}_{2}$, whereas the rest of the peaks are due to the $\mathrm{HfO}_{2}$ monoclinic phase. So, FTIR measurements can be used to check the crystalline structure of $\mathrm{HfO}_{2}$ films.

Figure 2 also shows an absorption band between 1200 and $1000 \mathrm{~cm}^{-1}$ characteristic of an asymmetric stretching vibration of the $\mathrm{SiO}_{4}$ unit [24]. We attribute these bands to the formation of an interfacial $\mathrm{SiO}_{2}$ layer between the $\mathrm{HfO}_{2}$ film and the $\mathrm{Si}$ substrate during the deposition. The maximum is situated at $1064 \mathrm{~cm}^{-1}$ irrespective of $R$, except for the sample deposited with only argon. In this case, the maximum shifts to $1072 \mathrm{~cm}^{-1}$. The shift to lower wave numbers with respect to the maximum of thermally grown 


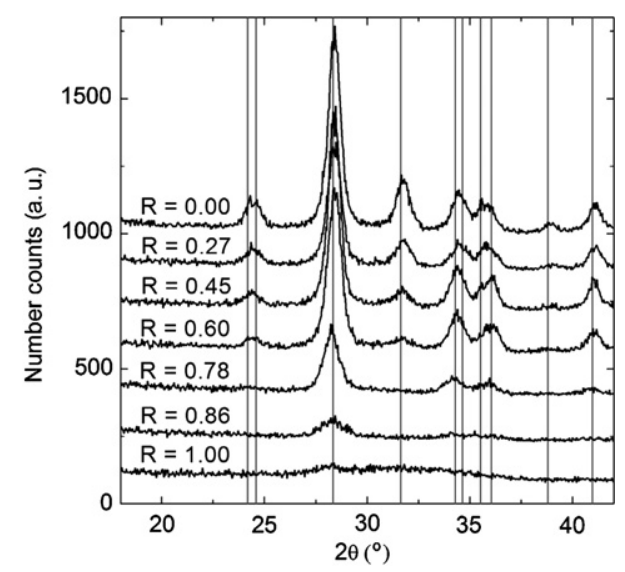

Figure 1. XRD diagrams from samples deposited at different $R$ values. The diffraction patterns of monoclinic $\mathrm{HfO}_{2}$ are highlighted with vertical lines.

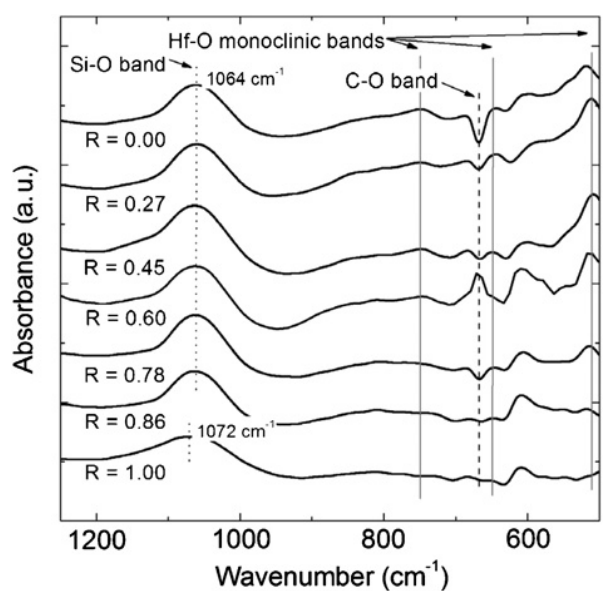

Figure 2. Infrared spectra showing peaks associated with $\mathrm{HfO}_{2}$ and $\mathrm{SiO}_{2}$ for samples deposited at different $R$ values.

$\mathrm{SiO}_{2}\left(1074.5 \mathrm{~cm}^{-1}\right)$ [25] is normally related to strain in the $\mathrm{SiO}_{2}$ film [24]. The polycrystalline structure of the $\mathrm{HfO}_{2}$ films deposited with oxygen-containing atmosphere may be responsible for the higher strain in the $\mathrm{SiO}_{2}$ interfacial layer. This can explain the shift to lower wave numbers. In the amorphous films, this strain is relaxed and the wave number for this films shifts to a value close to the thermally grown $\mathrm{SiO}_{2}$.

The cross-sectional TEM images of $\mathrm{HfO}_{2}$ films deposited at different $R$ ratios were obtained to confirm the HPRS $\mathrm{HfO}_{2} / \mathrm{SiO}_{2}$ stacked structure. In all the images, a dark layer was observed on top of a thinner amorphous film. The amorphous films were identified as $\mathrm{SiO}_{2}$, in agreement with the FTIR results. The electron diffraction patterns of the $\mathrm{HfO}_{2}$ films deposited in atmospheres containing oxygen can be explained by a polycrystalline monoclinic phase, further supporting the FTIR and XRD results. Therefore, the results obtained by XRD, FTIR and TEM led us to assume that the transition from $\mathrm{HfO}_{2}$ polycrystalline films to amorphous ones takes place for a value of $R$ higher than 0.86 . However, it is unfeasible to be precise about whether there is an exact value for this transition or that amorphous films are only grown in a pure Ar atmosphere.
Table 1. $\mathrm{HfO}_{x}$ and $\mathrm{SiO}_{x}$ film thickness obtained from TEM measurements.

\begin{tabular}{lll}
\hline$R$ parameter & $\begin{array}{l}\mathrm{SiO}_{x} \\
\text { thickness }(\mathrm{nm})\end{array}$ & $\begin{array}{l}\mathrm{HfO}_{x} \\
\text { thickness }(\mathrm{nm})\end{array}$ \\
\hline 0 & 3.74 & 20.58 \\
0.15 & 3.50 & 28.65 \\
0.37 & 3.30 & 27.84 \\
0.54 & 3.35 & 21.25 \\
0.67 & 4.50 & 19.44 \\
0.78 & 5.50 & 9.34 \\
0.86 & 4.60 & 5.97 \\
1 & 3.63 & 10.86 \\
\hline
\end{tabular}

Table 1 lists the $\mathrm{HfO}_{2}$ and $\mathrm{SiO}_{2}$ film thicknesses obtained by TEM images. Except for the samples deposited in a pure atmosphere of $\mathrm{O}_{2}$ or Ar, a decrease of the $\mathrm{HfO}_{2}$ thickness with increasing $R$ ratio is observed, as the XRD measurement suggested. The drop in the growth rate cannot be due to reduction of the efficiency of the transport of the sputtered particles, since the working pressure was kept constant for all the samples, and consequently a drastic decrease of neither the thermalization length nor the diffusion coefficient is feasible. Another possibility to explain the reduction of the growth rate may be a diminution of generation of sputtering particles, i.e., ionized particles. We tentatively attribute the possible drop of the plasma density to a decrease in the emission of secondary electrons from the target. On the one hand, secondary electrons cause ionization collisions that help to maintain the discharge. On the other hand, they are responsible for a significant power input to the anode [26]. In order to experimentally confirm the above hypothesis, the substrate temperature was measured as a function of $R$ ratio when the substrate is not deliberately heated. A substrate temperature ranging from 127 to $75^{\circ} \mathrm{C}$ is obtained when the $R$ ratio was varied from 0 to 1 . Hence, the incoming energy is higher when the oxygen content increases, indicating a higher density of secondary electrons. The ionization processes are more efficient providing a higher amount of sputtering particles and explaining the observed trend in the $\mathrm{HfO}_{2}$ film thickness.

As was stated previously, the thickness of the $\mathrm{HfO}_{2}$ film for $R=1$ breaks the explained tendency. The growth rate for the sample deposited in pure Ar plasma is much higher than 

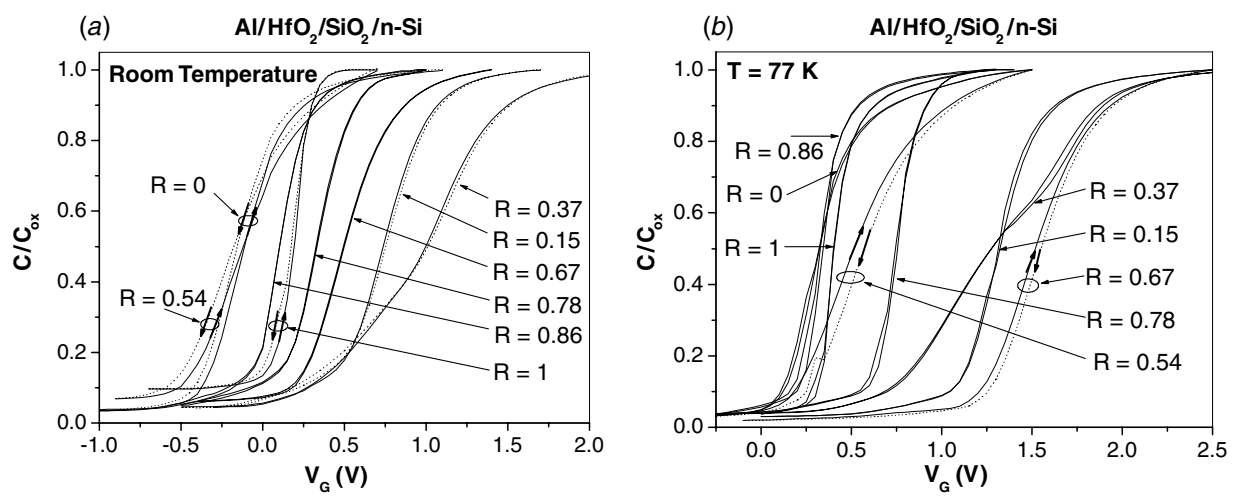

Figure 3. $1 \mathrm{MHz} C-V$ curves corresponding to $\mathrm{Al} / \mathrm{HfO}_{x} / \mathrm{n}-\mathrm{Si}$ MIS devices, measured at room temperature $(a)$ and at $77 \mathrm{~K}(b)$.

for the samples deposited with a small proportion of oxygen in the plasma. It may be explained by an enhancement of ionization rate, in spite of the reduction of the emission of secondary electrons with increasing $R$. The molecular motion and dissociation of the $\mathrm{O}_{2}$ molecules consumes energy, which is taken from the discharge plasma. Indeed, it was observed that the optical emission intensity of the plasma clearly decreases with a slight addition of oxygen to the Ar plasma [27]. In conclusion, this energy loss leads to a reduction in the ionization process, explaining the sharp decrease of the $\mathrm{HfO}_{2}$ growth rate with a small addition of oxygen in the plasma.

Table 1 also shows that the $\mathrm{HfO}_{2}$ and $\mathrm{SiO}_{2}$ thicknesses follow an inverse trend. The higher the thickness of the $\mathrm{HfO}_{2}$ films the lower the $\mathrm{SiO}_{2}$ interlayer thickness. This trend may be described by the oxidation action and diffusion of the $\mathrm{O}$ radicals present in the chamber as follows.

Firstly, we have to keep in mind that the sputtering gas is not the only source of oxygen, but also the $\mathrm{HfO}_{2}$ target and the residual gas and contamination of the chamber are other possible sources of oxygen. At the beginning of the deposition process, the highly reactive oxygen radicals present in the sputtering system oxidize the silicon surface [28]. As the deposition process advances, the oxidation process is limited by the formation of the $\mathrm{HfO}_{2}$ films. The subsequent $\mathrm{SiO}_{2}$ formation is due to the diffusion process through the $\mathrm{HfO}_{2}$ film. The oxygen diffuses through the $\mathrm{HfO}_{2}$ film, reaches the silicon substrate and reacts to form silicon oxide. The $\mathrm{SiO}_{2}$ growth rate due to diffusion is reduced as the $\mathrm{HfO}_{2}$ film gets thicker.

The two mechanisms taken into account to explain the formation of the $\mathrm{SiO}_{2}$ layer lead to the conclusion that the $\mathrm{SiO}_{2}$ thickness of the interlayer should be lower when the $\mathrm{HfO}_{2}$ growth rate is higher, so that the formation of the $\mathrm{HfO}_{2}$ film avoids the silicon oxidation and reduces the subsequent diffusion of oxygen.

\subsection{Electrical measurements}

$1 \mathrm{MHz} C-V$ curves, measured at 300 and $77 \mathrm{~K}$, are shown in figure 3. According to data appearing in the literature $[29,30]$, the work function of aluminium in hafnium oxide is about $4.25 \mathrm{eV}$ which yields a theoretical value of about $-0.25 \mathrm{~V}$ for the flat-band voltage of $\mathrm{Al} / \mathrm{HfO}_{2} / \mathrm{Si}$ capacitors. Samples processed by using high $R$ values exhibit very good

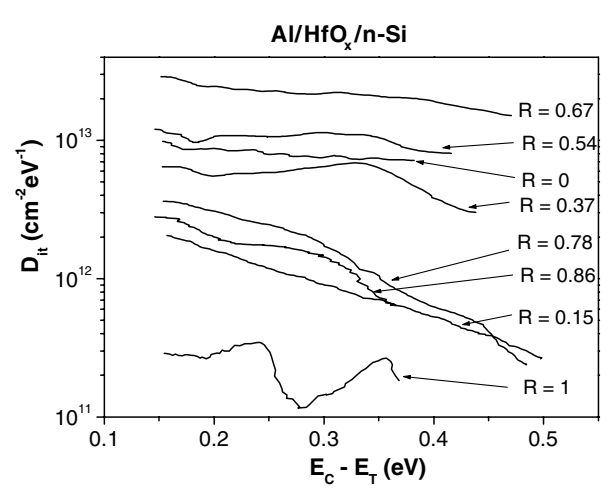

Figure 4. Interfacial state densities measured by using DLTS on $\mathrm{Al} / \mathrm{HfO}_{x} / \mathrm{n}$-Si MIS devices.

characteristics with flat-band voltage close to the theoretical value. Indeed, $R=0.86$ and $R=1$ provide the best results. In contrast, $R=0.15$ and $R=0.37$ give $C-V$ curves with considerable flat-band voltage shifts to positive values, denoting the presence of negative fixed charges throughout the dielectric. The sample processed by using $R=0$ has better $C-V$ curves than those corresponding to $R=$ 0.15 and $R=0.37$. As for $R=0.78$ and $R=0.67$ processed samples, their flat-band voltage clearly shifts to positive values, especially in the $R=0.67$ case at low temperature. Also, $C-V$ characteristics corresponding to the $R=0.37$ processed sample have a considerable stretch-out, both at room temperature and at $77 \mathrm{~K}$. This strong stretchout cannot be explained only by the surface state density at the insulator-silicon interface $D_{\mathrm{it}}$, since this sample exhibits lower values than samples with $R=0$ and 0.54 (figure 4). We suggest the existence of a certain density of states localized at the $\mathrm{HfO}_{2} / \mathrm{SiO}_{2}$ interface to explain these stretch-out differences. Apart from the negative charge distributed in the dielectric bulk, the charge trapped at this interface can also contribute to the high positive flat-band voltage exhibited by some samples $(R=0.15,0.37,0.67$ and 0.78$)$. This low quality interface can also be related to the film thickness: the thicker samples must correspond to less dense and, i.e., lower quality insulator films.

Finally, $C-V$ curves of $R=0.54$ processed sample do not exhibit a great flat-band voltage shift, but they have a considerable amount of hysteresis, even at $77 \mathrm{~K}$. At low 
(a) $\mathbf{A l} / \mathrm{HfO}_{\mathbf{x}} / \mathbf{n}-\mathrm{Si}$ Room Temperature

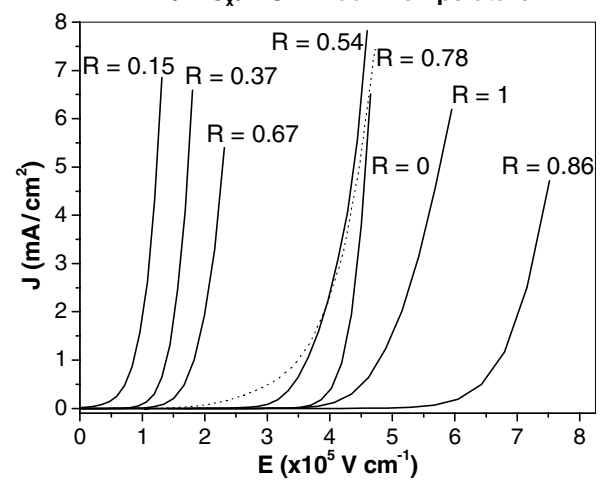

(c) $\quad \mathrm{Al} / \mathrm{HfO}_{2} / \mathrm{SiO}_{2} / \mathrm{n}-\mathrm{Si} \quad \mathrm{R}=1.0$

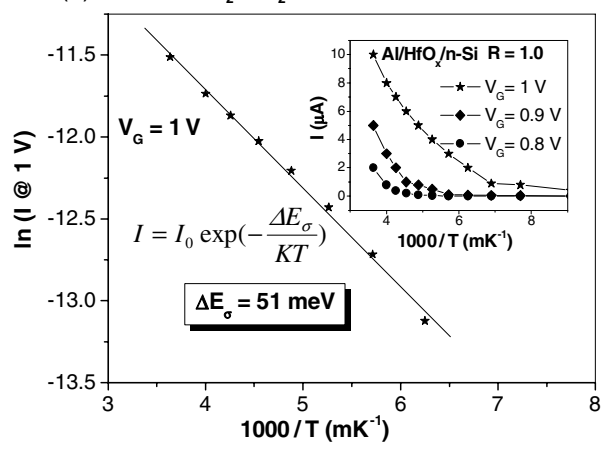

(b)

$\mathrm{Al} / \mathrm{HfO}_{2} / \mathrm{SiO}_{2} / \mathrm{n}-\mathrm{Si}$

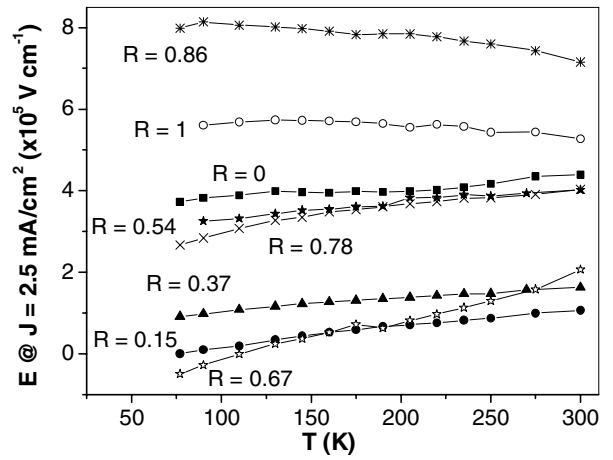

(d) $\quad \quad \quad \mathbf{A l} / \mathrm{HfO}_{2} / \mathrm{SiO} / \mathrm{n}-\mathrm{Si} \quad \mathrm{R}=\mathbf{0 . 8 6}$

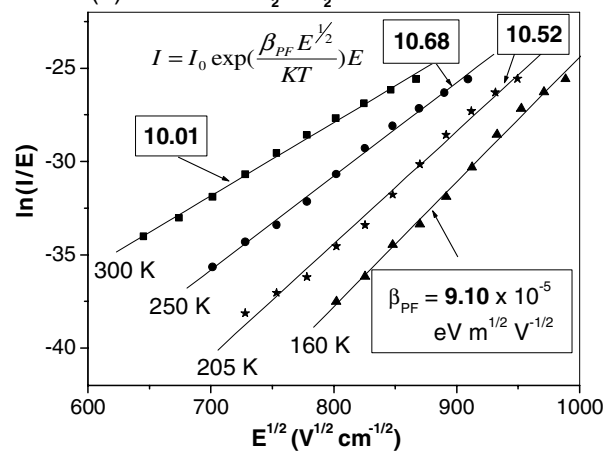

Figure 5. Room-temperature current density, $J$, against $\left(V_{\mathrm{G}}-V_{\mathrm{FB}}\right)$ curves $(a)$, and $\left(V_{\mathrm{G}}-V_{\mathrm{FB}}\right)$ values corresponding to $2.5 \mathrm{~mA}$ cm ${ }^{-2}$ current density as a function of temperature $(b)$ for $\mathrm{Al} / \mathrm{HfO}_{x} / \mathrm{n}-\mathrm{Si}$ MIS devices. Temperature dependence of the current measured at $V_{\mathrm{G}}=1 \mathrm{~V}$ corresponding to the $R=1$ processed sample $(c)$. Current-electric field dependence at several temperatures for the $R=0.86$ processed sample $(d)$

temperature only $R=0.54$ and $R=0.67$ processed samples exhibit hysteresis phenomena, whereas room temperature $C-V$ curves corresponding to $R=0.54,0$ and 1 processed samples have considerable hysteresis behaviour. It is worth pointing out that for the only sample in which there are hysteresis phenomena both at room temperature and at $77 \mathrm{~K}$ (the $R=$ 0.54 processed sample), the hysteresis cycle is clockwise at $77 \mathrm{~K}$, whereas it reverses to counter-clockwise at room temperature. This effect is strongly related to the shape of flat-band transients, as will be shown later. Figure 4 shows interfacial state densities obtained from DLTS for all the $R$ values. The lowest $D_{\text {it }}$ density corresponds to the $R=1$ processed sample $\left((1-3) \times 10^{11} \mathrm{~cm}^{-2} \mathrm{eV}^{-1}\right)$. In contrast, the $R=0.67$ processed sample exhibits the highest $D_{\text {it }}$ density $\left((2-3) \times 10^{13} \mathrm{~cm}^{-2} \mathrm{eV}^{-1}\right)$. The rest of the samples have intermediate interfacial state density values. To $R=0.54,0$ and 0.37 processed samples correspond $D_{\text {it }}$ values near to $1 \times$ $10^{13} \mathrm{~cm}^{-2} \mathrm{eV}^{-1}$ : $(1-2) \times 10^{13}$ for $R=0.54,(9-10) \times 10^{12}$ for $R=0$ and (6-8) $\times 10^{12} \mathrm{~cm}^{-2} \mathrm{eV}^{-1}$ for $R=0.37$. In contrast, to $R=0.78,0.86$ and 0.15 processed samples correspond lower

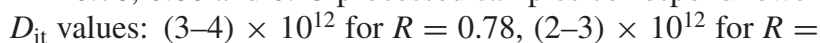
0.86 and $(1-2) \times 10^{12} \mathrm{~cm}^{-2} \mathrm{eV}^{-1}$ for $R=0.15$. As has been said before, samples processed by using argon-rich plasma have a considerable amount of residual hydrogen, which probably contributes to the dangling bond passivation. This fact could explain why low interfacial state densities correspond to the samples processed by using high $R$ values.

Figure 5 shows current measurement results under positive gate bias at several temperatures between 77 and
$300 \mathrm{~K}$. The leakage current is higher at a positive bias than at a negative bias, because the charge conduction is controlled by the metal-oxide interface instead of by the silicon-oxide interface [31]. Also, saturation of the current in inversion (negative bias for a $\mathrm{n}-\mathrm{Si}$ substrate) is produced due to the exhausting of the minority carriers injected from the substrate [32]. So, the results obtained under positive bias are the best indicator of film quality [33, 34].

Room temperature current density as a function of the insulator electric field for different $R$ parameter values is shown in figure 5(a). Electric field values instead of gate voltage are displayed to take into account the variation in the insulator thickness for the different samples. To calculate the electric field in the insulator we have taken into account that the effective voltage drop in the insulator is the difference between the gate voltage applied, $V_{\mathrm{G}}$, and the flat-band voltage, $V_{\mathrm{FB}}$. In figure $5(b)$, the electric field values at $2.5 \mathrm{~mA} \mathrm{~cm}{ }^{-2}$ current density, at temperatures between 77 and $300 \mathrm{~K}$, are displayed for all the samples. In these figures we observe that the thicker the sample the lower the onset electric field (figure 5(a)) and the field at a given current density (figure $5(b)$ ). There is a clear correlation between the conduction behaviour and $C-V$ curves: samples having high flat-band voltage and stretch-out in $C-V$ curves provide higher currents. This fact confirms that the insulator quality improves when we obtain well-densified films. In consequence, the electrical behaviour of the insulator is mainly limited by the film quality itself and the effect of impurities like boron, carbon 

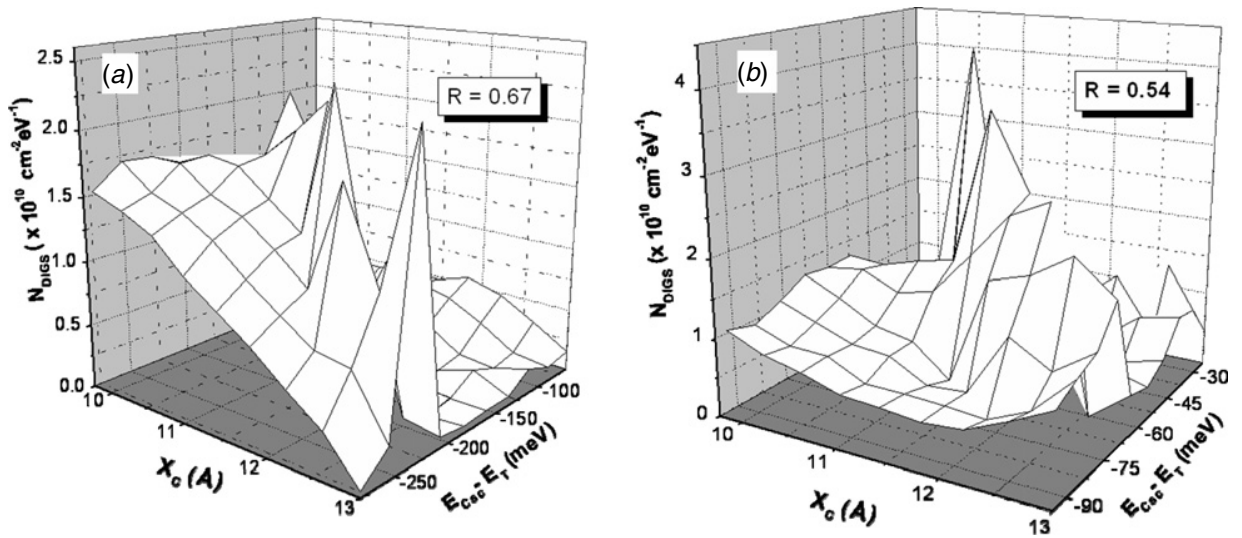

Figure 6. DIGS density obtained from conductance transients corresponding to the $R=0.67(a)$ and $R=0.54(b)$ processed samples. The spatial distance to the dielectric/silicon substrate interface is denoted by $x_{\mathrm{c}}$, and $E_{\mathrm{T}}$ is the energy position with respect to the silicon conduction band edge.

Table 2. Activation energy values and Poole-Frenkel coefficients obtained from current measurements.

\begin{tabular}{lccl}
\hline $\begin{array}{l}R \\
\text { parameter }\end{array}$ & $\Delta E_{\sigma}(\mathrm{meV})$ & $\begin{array}{l}\beta_{\mathrm{PF}}\left(10^{-5} \mathrm{eV}\right. \\
\left.\mathrm{m}^{1 / 2} \mathrm{~V}^{-1 / 2}\right)\end{array}$ & $\begin{array}{l}\mathrm{P}-\mathrm{F} \text { fit electric } \\
\text { field range } \\
\left(\mathrm{MV} \mathrm{cm}^{-1}\right)\end{array}$ \\
\hline 0 & $101-100$ & 11.11 & $(0.1-0.3)$ \\
0.15 & $103-100$ & 9.69 & $(0.2-0.3)$ \\
0.37 & $69-50$ & 14.88 & $(0.1-0.2)$ \\
0.54 & $158-150$ & 9.81 & $(0.1-0.3)$ \\
0.67 & $148-150$ & 13.33 & $(0.1-0.3)$ \\
0.78 & $101-100$ & 9.84 & $(0.1-0.3)$ \\
0.86 & $149-150$ & 10.01 & $(0.4-0.7)$ \\
1 & $51-50$ & 11.61 & $(0.3-0.5)$ \\
\hline
\end{tabular}

or fluorine must be neglected in this case. We suggest that the most important factor is the high density of oxygen vacancies typically appearing in high- $k$ dielectrics.

Figure $5(c)$ shows the current-temperature dependence for the $R=1$ processed sample. In the 150-300 K temperature range the relationship between $\ln (I)$ and $1000 / T$ is clearly linear. This Arrhenius plot indicates a conduction mechanism controlled by Poole-Frenkel emission, since it is known that for Schottky emission mechanism an Arrhenius plot of $\ln \left(I / T^{2}\right)$ against 1000/T is fitted. The Poole-Frenkel mechanism, bulk limited, relies on the traps in the insulator, and it is associated with the field-enhanced thermal excitation of charge carriers from traps. As shown in the inset, the slopes of the lines do not vary appreciably with the applied voltage, indicating that the conduction takes place through an activated process having a single activation energy, $\Delta E_{\sigma}$, which follows the relation [35]

$$
I=I_{0} \exp \left(-\frac{\Delta E_{\sigma}}{K T}\right) .
$$

The activation energy values corresponding to all the samples are listed in table 2 . It is worth pointing out that the activation energy values obtained for $R=1$ and 0.37 processed samples correspond to the previously reported soft-optical phonon energy (of about $50 \mathrm{meV}$ ), obtained from flat-band transient measurements [36]. Moreover, all obtained activation energy values are about twice this value $(R=0,0.15$ and 0.78$)$ or about three times this value $(R=0.54,0.67$ and 0.86$)$.

Figure $5(d)$ shows the plot of $I / E$ (in logarithmic scale) against $E^{1 / 2}$ at several temperatures, corresponding to the $R=$
0.86 processed sample. There is a linear dependence, as required by the Poole-Frenkel equation [37]

$$
I=I_{0} \exp \left(\frac{\beta_{\mathrm{PF}} E^{1 / 2}}{K T}\right) E .
$$

The obtained value of $\beta_{\mathrm{PF}}$ in the $0.4-0.7 \mathrm{MV} \mathrm{cm}{ }^{-1}$ electric field range is about $10 \times 10^{-5} \mathrm{eV} \mathrm{m}^{1 / 2} \mathrm{~V}^{-1 / 2}$ at temperatures between 160 and $300 \mathrm{~K}$. The room-temperaturemeasured Poole-Frenkel field-lowering coefficient values, $\beta_{\mathrm{PF}}$, corresponding to all the samples, as well as the electric field range where the linear behaviour has been observed, are listed in table 2. $\beta_{\mathrm{PF}}$ parameter is nearly the same for all the $R$ values, varying between $(10-15) \times 10^{-5} \mathrm{eV} \mathrm{m}^{1 / 2} \mathrm{~V}^{-1 / 2}$. The theoretical value of $\beta_{\mathrm{PF}}$ obtained from the dielectric constant of $\mathrm{HfO}_{2}$ layer at optical frequencies (about 3.6) is $4 \times$ $10^{-5} \mathrm{eV} \mathrm{m}^{1 / 2} \mathrm{~V}^{-1 / 2}$. So, despite the good fit of Poole-Frenkel plots, the experimental and theoretical values do not agree. This difference must be related to the physical structure of the films, in which an interfacial layer is clearly observed, as has been said above.

Conductance transients are very small for all the samples due to the $\mathrm{SiO}_{2}$ layer existing between the silicon substrate and the $\mathrm{HfO}_{2}$ film [38]. It has only been possible to measure DIGS densities for the $R=0.54$ and 0.67 processed samples, both exhibiting the greatest hysteresis phenomena in $C-V$ curves [39] (figure 3). In the rest of the samples (except $R=$ 0 and 1 at room temperature) hysteresis is negligible in the entire temperature range, and so appreciable conductance transients are not expected. Three-dimensional graphs of 
disordered-induced-gap-states (DIGS) density as a function of energy position and spatial coordinate [40], corresponding to both samples, are shown in figure 6. The experimental setup allows building this plot for distances in the range from 1.0 to $1.3 \mathrm{~nm}$ from the silicon substrate, lower and higher depths in the insulator film would require very short and very long, respectively, time constants that are not available on the lock-in amplifier used by us. For the $R=0.67$ processed sample (figure 6(a)), DIGS density reaches values up to $1.5 \times 10^{10} \mathrm{~cm}^{-2} \mathrm{eV}^{-1}$ located in the insulator at about 10-12 $\AA$ from the dielectric/semiconductor interface and at energy positions between 75 and $275 \mathrm{meV}$ measured from the semiconductor conduction band. That does not mean that DIGS density was maximum at these locations since we have not recorded values for other depths. As for the $R=0.54$ processed sample (figure $6(b)$ ), DIGS density reaches values up to $3 \times 10^{10} \mathrm{~cm}^{-2} \mathrm{eV}^{-1}$ also located at about 10-12 $\AA$ from the dielectric/semiconductor interface, but at energy positions between 25 and $80 \mathrm{meV}$ measured from the semiconductor conduction band. The different energetic range in both samples is correlated with the temperature range in which conductance transients having high enough amplitude have been found for each sample.

Figure 7 shows flat-band voltage transients, recorded by keeping the capacitance constant at the flat-band condition. These measurements give information about phonon-assisted tunnelling mechanisms between localized states in the band gap of the insulator [36]. As expected, $R=0.54$ and 0.67 processed samples exhibit the greatest amplitude transients, since flat-band transients, similarly to conductance transients, are related to the hysteresis behaviour in $C-V$ curves. In figure $7(a)$, normalized flat-band transients measured at different temperatures corresponding to several samples are displayed together. As shown elsewhere [36], the transient amplitude decreases when the temperature decreases. Transient amplitudes of the $R=0.54$ processed sample go up to $100 \mathrm{mV}$ at temperatures above $150 \mathrm{~K}$. However, the amplitude of flat-band transient measured at $250 \mathrm{~K}$ corresponding to the $R=0.67$ processed sample is only slightly higher than those measured at $77 \mathrm{~K}$ corresponding to $R=0.54$ processed sample. For the rest of the samples, room temperature transients have even lower amplitude than those measured at $77 \mathrm{~K}$ corresponding to $R=0.54$, as shown in figure $7(a)$ for the $R=0$ case.

As for transient shape, it depends on the initial polarization state of the sample. Indeed, in figure $7(b)$ it appears that at room temperature the transient corresponding to the $R=$ 0.54 processed sample increases (decreases) when the initial bias condition corresponds to the accumulation (inversion) regime. Indeed, as mentioned above, room temperature $C-V$ curves of this sample exhibit counter-clockwise hysteresis. When the initial steady state belongs to the accumulation regime, capacitance reaches the flat-band value following the left $C-V$ curve (marked in figure 3(a) by means of a decreasing arrow), and so bias voltage must go to less negative values in order to reach the final steady state. The contrary occurs when the sample is initially biased in the inversion regime: capacitance follows the right $C-V$ curve and bias voltage evolves to more negative values. After enough time both
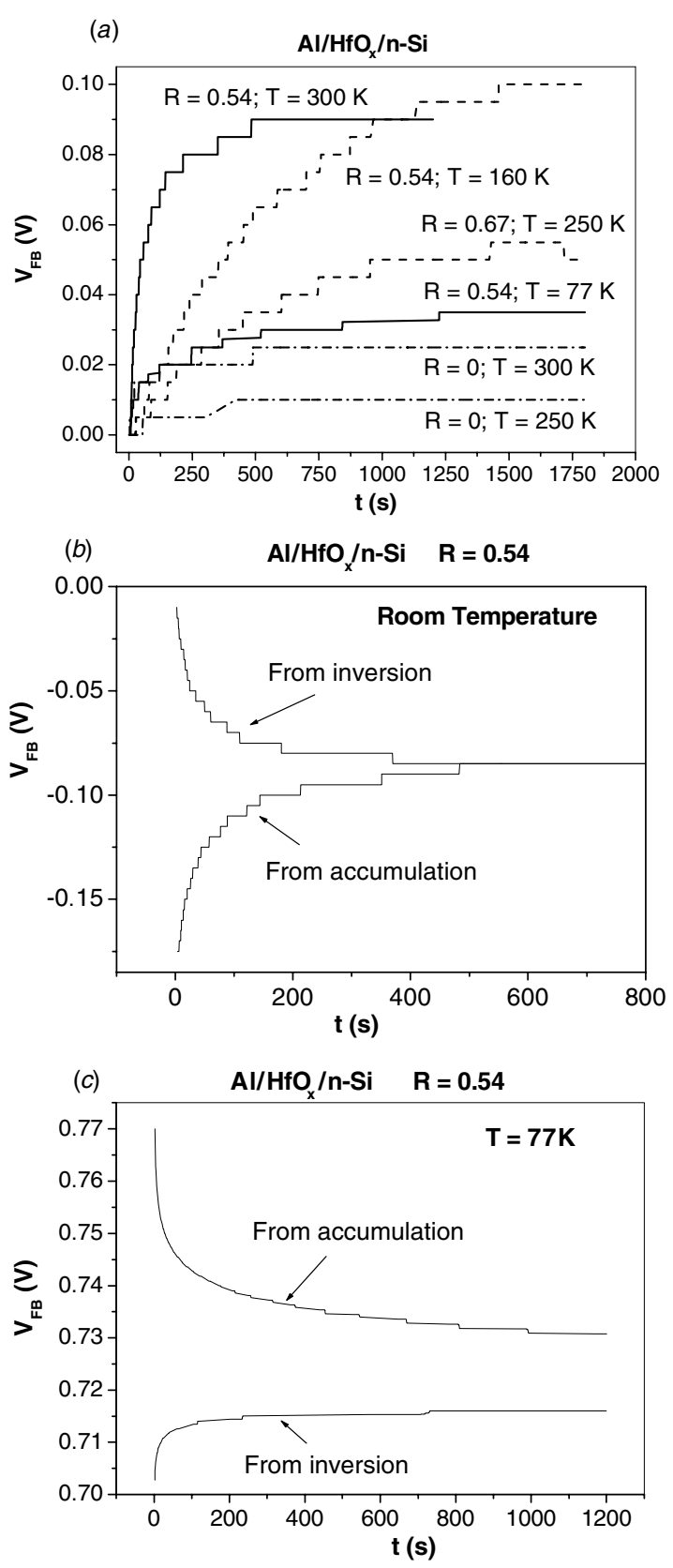

Figure 7. Normalized flat-band transients measured at several temperatures corresponding to the $R=0.54, R=0.67$ and $R=0$ processed samples $(a)$. Flat-band transients measured at room temperature $(b)$ and at $77 \mathrm{~K}(c)$, corresponding to the $R=0.54$ processed sample.

voltage transients reach the same final value, as shown in figure $7(b)$.

In figure $7(c)$, flat-band transients corresponding to the same sample but measured at $77 \mathrm{~K}$ are shown. Since $C-V$ curves at this temperature exhibit clockwise hysteresis (figure 3(b)), flat-band transients increase when the sample is initially biased in inversion, whereas transients decrease when the initial state belongs to the accumulation regime. As is apparent in figure 7(c), although both branches clearly approach one another, the transients are so slow that a large amount of time would be needed in order to reach the same final value at this low temperature. 


\section{Summary}

The physical properties and growth kinetics of $\mathrm{HfO}_{2}$ films deposited by HPRS in different $\mathrm{O}_{2} / \mathrm{Ar}$ plasmas have been studied. Except for the sample deposited in pure Ar, the $\mathrm{HfO}_{2}$ growth rate decreases with increasing $\mathrm{O}_{2}$ proportion in the plasma, which is attributed to the less efficient emission of secondary electrons. When $\mathrm{O}_{2}$ is completely removed from the plasma $(R=1)$, the ionization rate is increased due to the cessation of energy consumption by molecular motion and dissociation process of the $\mathrm{O}_{2}$ molecules, explaining the increase of the growth rate for $R=1$. Several techniques showed that the $\mathrm{HfO}_{2}$ films deposited in atmosphere containing $\mathrm{O}_{2}$ were polycrystalline, unlike the films deposited in pure $\mathrm{Ar}$ that were amorphous. The formation of an interfacial $\mathrm{SiO}_{2}$ layer between the high- $k$ dielectric and the Si-substrate has been detected by FTIR and TEM, which limits the possibilities of this system to obtain small equivalent oxide thickness. However, the structural modification as a function of the sputtering conditions is an interesting result from the physics point of view.

The electrical characteristics of metal-oxidesemiconductor capacitors with high-pressure-reactively sputtered hafnium oxide gate dielectrics were investigated. The argon flow to argon plus oxygen flow ratio of the pulverization gas mixture, $R$, was varied between 0 (only oxygen) and 1 (only argon). Films deposited with $\mathrm{O}_{2}$ plasma or mixed $\mathrm{O}_{2} /$ Ar plasmas are polycrystalline, only those grown by using pure argon plasma are amorphous. Amorphous films show the best characteristics in terms of capacitance-voltage behaviour, leakage current and interfacial state density. We have observed that the electrical performance of the films improves when we obtain well-densified films. On the other hand, samples fabricated by using $R=0.54$ and 0.67 exhibit considerable conductance and flat-band voltage transients. From the applied voltage and temperature dependences of the leakage current it is shown that Poole-Frenkel is the main conduction mechanism in all samples.

\section{Acknowledgments}

The study was partially supported by the local government (Junta de Castilla y León) under Grant No VA018A06 and by the Spanish TEC2005 under Grant No 05101/MIC. The authors acknowledge CAI de Técnicas Físicas, CAI de Espectroscopía y Espectrometría and CAI de Microscopía y Citometría of the Universidad Complutense de Madrid for technical support. This work was made possible thanks to the AP2003-4434-FPU grant of the Spanish MEC and the contract TEC 2004-1237/MIC of the Spanish MCYT

\section{References}

[1] Robertson J 2006 Rep. Prog. Phys. 69327

[2] Green M L, Gusev E P, Degraeve R and Garfunkel E L 2001 J. Appl. Phys. 902057

[3] Gusev E P, Lu M C, Garfunkel E, Guftafson T and Green M L 1999 IBM Res. Dev. 43265

[4] Habraken F H P M and Kuiper A E T 1994 Mater. Sci. Eng. R 12123

[5] Wong H and Iwai H 2006 Micrelectron. Eng. 831867
[6] Wilk G D, Wallance R M and Anthony J M 2001 J. Appl. Phys. 895243

[7] Houssa M, Partisano L, Ragnarsson L- $\AA$, Degraeve R, Schram T, Pourtois G, De Gendt S, Groeseneken G and Heyns M M 2006 Mater. Sci. Eng. R 5137

[8] Callegari A et al 2004 IEDM Tech. Dig. (NJ: IEEE) p 825

[9] Quevedo-Lopez M A, Chambers J J, Visokay M R, Shanware A and Colombo L 2005 Appl. Phys. Lett. 87012902

[10] Watannabe T, Takayanagi M, Kojima K, Sekine K, Yamasaki H, Eguchi K, Ishimaru K and Ishiuchi H 2004 IEDM Tech. Dig. (NJ: IEEE) p 507

[11] International Technology Roadmap for Semiconductors 2006 [on line] Available at http://www.itrs.net/

[12] Kerber A, Cartier E, Pantisano L, Rosmeulen M, Degraeve R, Kauerauf T, Groeseneken G, Maes H E and Schwalke U 2003 Proc. 41 st Annu. Int. Reliability Physics Symp. p 41

[13] Kerber A, Cartier E, Pantisano L, Degraeve R, Groeseneken G, Maes H E and Schwalke U 2004 Microelectron. Eng. 72267

[14] Chowdhury N A, Garg R and Misra D 2004 Appl. Phys, Lett. 853289

[15] Degraeve R, Kerber A, Roussel P h, Cartier E, Kauerauf T, Pantisano L and Groeseneken G 2003 IEDM Tech. Dig. (NJ: IEEE) p 935

[16] Shickova A, Kaczer B, Simoen E, Verheyen P, Eneman G, Jurczak M, Absil P, Maes H and Groeseneken G 2007 Micrelectron. Eng. 841906

[17] Alam M A 2003 IEDM Tech, Dig. (NJ: IEEE) p 345

[18] San Andrés E, Toledano-Luque M, Prado A, Navacerrada M A, Mártil I, González-Díaz G, Bohne W, Röhrich J and Strub E 2005 J. Vac. Sci. Technol A 231523

[19] Thornton J A 1974 J. Vac. Sci. Technol. 11666

[20] Toledano-Luque M, San Andrés E, Prado A, Mártil I, González-Díaz G, Martínez F L, Bohne W, Röhrich J and Strub E 2007 J. Appl. Phys. 102044106

[21] Toledano-Luque M, San Andrés E, Olea J, Prado A, Mártil I, Bohne W, Röhrich and Strub E J 2006 Mater. Sci. Semicond. Proc. 91020

[22] Kern W and Puotinen D S 1970 RCA Rev. 31187

[23] Hann R E, Suitch P R and Pentecost J L 1985 J. Am. Ceram. Soc 68 C-285

[24] Fitch J T, Kim S S and Lucovsky G 1990 J. Vac. Sci. Technol. A 81871

[25] Tsu D V 2000 J. Vac. Sci. Technol. B 181796

[26] Chapman B 1980 Glow Discharge Processes (New York: Wiley)

[27] Toledano-Luque M, Lucia M L, del Prado A, San Andrés E, Martil I and González-Díaz G 2007 Appl. Phys. Lett. submitted

[28] Tsui B and Chang H 2003 J. Appl. Phys. 9310119

[29] Yeo Y-C, Ranade P, King T-J and Hu C 2002 IEEE Electron Device Lett. 23342

[30] Yeo Y-C, King T-J and Hu C 2002 J. Appl. Phys. 927266

[31] Cho B O, Wang J, Sha L and Chang J P 2002 Appl. Phys. Lett. 801052

[32] Novkovski N and Atanassova E 2006 Appl. Phys. A 83435

[33] Yang W, Marino J, Monson A and Wolden C A 2006 Semicond. Sci. Technol. 211573

[34] Novkoski N 2006 Semicond. Sci. Technol. 21945

[35] Hegab N A and Atya H E 2006 J. Ovonic Res. 221

[36] Dueñas S, Castán H, García H, Bailón L, Kukli K, Ritala M and Leskelä M 2007 Microelectron. Reliab. 47653

[37] Frenkel J 1938 Phys. Rev. 54647

[38] Dueñas S, Castán H, García H, Barbolla J, Kukli K and Aarik J 2004 J. Appl. Phys. 961365

[39] Dueñas S, Peláez R, Castán H, Pinacho R, Quintanilla L, Barbolla J, Mártil I and González-Díaz G 1997 Appl. Phys. Lett. 71826

[40] Castán H, Dueñas S, Barbolla J, Redondo E, Blanco N, Mártil I and González-Díaz G 2000 Microelectron. Reliab. 40845 